\title{
FORMIDABLE ECHO
}

The USSR Council of Ministers has adopted the decision on adjustments in construction in the country's seismic areas. E. F. Savarensky, Chairman of the Council on Seismology and Earthquake Proof Construction, corresponding member, USSR Academy of Sciences, comments this decision.

It would be naive to speak of transferring the established industrial and cultural centres, with their wealth of national traditions, to other less dangerous places. Yet, it is quite a different thing when it comes to construction projects. The decision of the USSR Council of Ministers has made it incumbent on the local agencies, ministries and departments, the State Planning Committee of the USSR to establish new enterprises, research institutes, institutions of higher learning and other buildings, primarily in seismically favourable territories.

At present science can partially assess areas, from the angle of the danger of the underground element. For the first time in our country a map of seismic distribution of the USSR has been produced. And it is used as a foundation for planned construction. It shows the zones where tremors of over 7 points are possible so that there is danger for buildings and structures.

Yet, this is a survey map. Because even in a seismically unreliable area there are places with dry grounds that look as if cemented. These are reliable in tremors. Yet, one should be wary of loose soils full of water. Also most dangerous are the zones with crevices, ruptures in the earth's crust.

It is the duty of the researchers to detect such places and produce maps of detailed microdistribution of the areas of large cities and developing industrial complexes situated in zones where there may be tremors of 8 and more points. Such maps are indispensable for determining the future position of hydroelectric power station dams and other large structures. Under the decision of the government the micro-distribution maps are to be made in 1970-1973.

This decision gears researchers for a search of heralds of underground tremors. An earthquake is not a chance phenomenon, but a consequence of continuous processes in the depths of our planet. The world science so far has not defined the regularities of appearance of underground tremors, the moment of their arrival. Not a single country has yet the methods for forecasting earthquakes. And our scientists are engaged in a serious search in this vitally important area.
We know that sometimes before strong tremors there is a comparatively quick deformation of the earth's crust, with some of its blocks raising and others going down, etc. There are methods helping to trace such deformations. Yet, not all earthquakes are preceded by such phenomena. In some cases one can notice changes in the physical properties of the crust, for instance, resilient and magnetic. This can also be registered with special instruments. Quite often an earthquake is preceded by a change in the chemical composition of the water from abyssal sources: there are more quantities of this or that gas appearing in wells with mineral water. It is hard to expect the heralds of the formidable tremors to be the same everywhere and always.

To achieve success in forecasting underground processes it is necessary to have the joint efforts of specialists in different professions - geologists, geophysicists, seismologists, civil engineers and others working in different departments. By the decision of the government the cities of Tashkent, Alma-Ata, Frunze and others will have experimental proving grounds set up in them in 1971 and 1972. A major purpose in this case is to watch the deformation of the earth's crust and other phenomena, to define the heralds of earthquakes.

The investigations of scientists and specialists are aimed at providing an economically grounded method of earthquake-proof erection of buildings. The builder should know the additional stress in the structures. And for this purpose large buildings, dams and other complexes in seismically dangerous areas have special instruments installed in them that register the oscillations of various structures during tremors. It is planned to increase the output of such instruments.

The decision of the USSR Council of Ministers is aimed at making science and technology help reduce to the minimum the influence of the destructive force of underground tremors. At the same time the decision makes it incumbent on the science directly engaged in investigating semismic processes to develop and to enrich practice with achievements in forecasting earthquakes. 